\title{
SimTrainer: A Management Training Tool
}

\author{
Wade Stark and Sema E. Alptekin \\ Industrial and Manufacturing Engineering Department \\ Cal Poly - San Luis Obispo, CA 93407
}

The advent of the computer created an opportunity to simulate the effects of real life scenarios. This characteristic, being able to correct mistakes before they happen, has made simulation a popular and a frequently used decision making technique. The rapid changes in today's technology have created a challenging environment for those individuals involved in educating today's work force. As new technologies emerge, employees and students need to be trained on these manufacturing processes and procedures. The project presented in this paper uses simulation in the development of a computer-assisted instruction tool that is aimed at training managers of these new technologies in the areas of Manufacturing Planning and Control (MPC).

A virtual teacher has been created by using Microsoft Excel and ProModel, a simulation modeling tool. This simulationtbased trainer provides the user with the ability to ask "whatif" questions and with the answers to these questions. Several concepts of MPC such as Kanban and pull-push systems are modeled using ProModel. The first model that will be explained in the paper represants a Kanban system, modeled after an industrial manufacturing cell of an electronics manufacturing company in Silicon Valley. The Kanban model gives the user insight into how a Kanban system works by allowing the user first to make simple clanges and then visually see how the manufacturing system is affected. For instance, at the beginning of the Kanban model a prompt appears for the user to enter the rumber of Kanban cards that the test center and the connector stations are pulling. The user can make these changes and re-run the model as many times as desired until the user feels comfortable with how a kanban system works. The model has statistics that show up on the screen to help the user understand how these changes affect the performance of the system. These statistics include the current work-in-process (WIP) and the throughput through the hand assembly workcenters. The model is intended to be a self paced training tool that can help ask those pertinent "what-if" questions that have been inside the users mind for some time. If the user so desires, he or she can venture into ProModel and modify the program to answer more in deptl "what-if" questions. The models created for this project have been built to be dynamic (ability to answer "what-if" questions) and provide visual understanding that is lacking in most lectures.
The JIT/MRP model provides the user the same ability to make changes to the model and view how these results affect the overall system. These models are intended to give the Manufacturing Planning and Control (MPC) managers a visual tool for understanding resource management issues such as the differences between MRP and JIT systems. Details of the computer-aided training tool and the results of our preliminary experiments will be provided in the paper. 